\title{
Ulcerative Lesions in Behcet's Disease
}

\author{
Ümit Türsen $^{1}$ and Belma Türsen ${ }^{2}$ \\ ${ }^{1}$ Department of Dermatology, School of Medicine, Mersin University, 33079 Mersin, Turkey
}

${ }^{2}$ Department of Dermatology, Mersin State Hospital, Mersin, Turkey

Correspondence should be addressed to Ümit Türsen, utursen@mersin.edu.tr

Received 8 June 2012; Revised 11 September 2012; Accepted 1 October 2012

Academic Editor: Marco A. C. Frade

Copyright ( $) 2012$ Ü. Türsen and B. Türsen. This is an open access article distributed under the Creative Commons Attribution License, which permits unrestricted use, distribution, and reproduction in any medium, provided the original work is properly cited.

Ulcerative lesions in Behcet's disease (BD) are regarded as important manifestation for diagnosis. Various kinds of ulcerative lesions appear in patients with BD. They present as orogenital ulcers, necrotizing vasculitis and pyoderma gengrenosum. Gastrointestinal system involvement (Gis) in Behçet's disease affects all areas from the esophagus to the anus. Most authors believe that the Gis manifestations of Behçet's disease should be confined to aphthous ulcers, which can occur throughout the Gis tract. All patients with oro-genital and Gis ulcerations should be fully investigated to establish a definitive diagnosis and eliminate the possibility of an underlying BD.

\section{Introduction}

BD was first defined by Behçet, a Turkish Professor of Dermatology, in 1937 as a triad of recurrent aphthous stomatitis, genital aphthae, and relapsing uveitis [1]. During the ensuing 65 years multiple systemic associations of the disease including articular, vascular, gastrointestinal, cardiopulmonary and neurologic involvement have become increasingly apparent [2-4]. Although the etiology and pathogenesis is not clearly defined, genetic predisposition, infections and immunological dysfunctions have been implicated [5]. BD has been reported worldwide, but has a distinct geographic distribution, with highest prevalences in countries along the ancient silk route. Although much has been learned during recent years on the pathogenesis and treatment of the disease, it is still an important cause of morbidity and mortality in areas where it is prevalent [3]. Young individuals are most commonly affected. Male to female ratio is usually $1: 1$. The gender predominance is different according to the prevalent countries. So $\mathrm{M}: \mathrm{F}$ ratio $1: 1$ seems to be not always correct [4]. Ocular and central nervous system involvement are the basic prognostic factors in BD. Cardiovascular, pulmonary, and gastrointestinal system involvements are the major causes of mortality. In different series, high prevalence of ocular, nervous system, pulmonary system involvement, large vessel thrombosis, thrombophlebitis and patergy positivity has been found in male patients, and in view of these data a more severe course in male patients can be expected. Higher incidence of severe clinical course and systemic involvement is observed when early onset of the disease is present [2-4].

\section{Ulcerative Clinical Manifestations}

Ulcerative lesions in $\mathrm{BD}$ are regarded as important manifestation for diagnosis. Various kinds of ulcerative mucocutaneous and Gis lesions appear in patients with BD.

2.1. Mucocutaneous Ulcerative Lesions. Mucocutaneous ulcerations are the most common presenting symptoms of the disease.

Oral Ulcers. Oral ulcer (or aphthae) is localized, painful, shallow, round to oval ulcer often covered by a gray fibromembranous slough and surrounded by an erythematous halo (Figure 1). They are seen as minor or major ulcerations, sometimes with herpetiform distribution at any site in the oral cavity. International study group criteria do not permit diagnosis in the absence of oral aphthae, and oral 


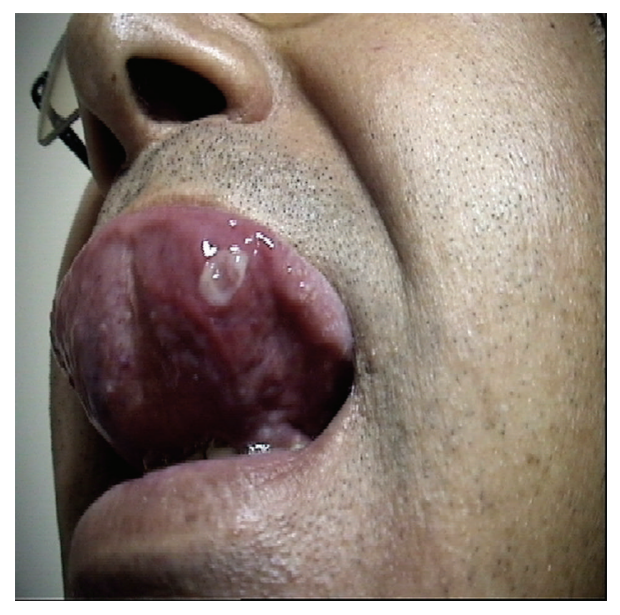

FIgURE 1: Oral ulcers.

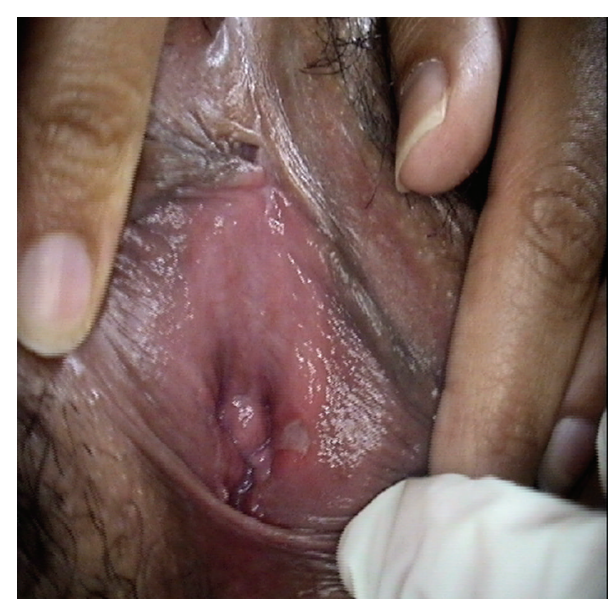

Figure 2: Genital ulcers. aphthae was seen in all patients with $\mathrm{BD}$. The vast majority of mild cases present with recurrent aphthous ulcerations of the oral mucosa which are usually the earliest and universal sign of the disease that are indistinguishable from common aphthae-canker sores in appearance and localization and has a yellowish necrotic base. This is frequently the first symptom and can precede the other manifestations of the syndrome by many years. Minor aphthous ulcers $(<10 \mathrm{~mm}$ in diameter) are the most common type $(85 \%)$; major or herpetiform ulcers are less frequent. Such mouth ulcers may be so painful that the patient is unable to eat during the attack. Aphthae may evolve quickly from a pinpoint flat ulcer to a large sore. In addition, intervals between recurrences range from weeks to months and typically may precede the onset of ocular, central nervous system, and some other systemic findings by many years. Smokers often experience a relapse of oral ulcers after quitting and nicotine replacement patches have been suggested to be useful in $\mathrm{BD}[2,4-7]$.

Genital Ulcers. In previous reports the prevalence of genital ulceration (or aphthae) was found to be between 60 and 90\% (Figure 2). Genital lesions were most commonly seen on the scrotum of male patients and on the vulva of female patients and tended to be larger and deeper in the female patients, sometimes even leading to perforations. The ulcers usually heal in 2-4 weeks; large ulcers frequently leave a scar whereas small ulcers and those on the minor labia heal without leaving a mark $[2,4,5,7]$. Genital ulcers are the second most commonly observed onset manifestation and resemble their oral counterparts. However, they are larger and deeper than mouth lesions, and appear at some time during the course of the disease $[2,4]$.

Otherskin Ulcerations. Other skin ulcerations, such as extragenital skin ulcers in the axillary and interdigital areas, pyoderma gangrenosum, leucocytoclastic vasculitis, polyarteritis-like cutaneous lesions, true arterial lesions, subungual infarctions, are less common [8].
Extragenital Ulcers. Extragenital ulcers occur in about \%3 of patients (Figure 3). They are common in children with BD and these recurrent ulcers usually heal with mild scarring [8]. Skin biopsies of extragenital ulcerations showed vasculitis $[9,10]$. Extragenital ulcers look like aphthous ulcers and commonly heal leaving a round atrophic scar. They are common in children with BD [8].

\section{Pyoderma Gangrenosum. Pyoderma gangrenosum-like} lesions are extremely rare. Pyoderma gangrenosum is a neutrophilic dermatitis with the same hypersensitivity to trauma as $\mathrm{BD}$. In pyoderma gangrenosum some cases are associated with bowel disease as in BD. Also, pyoderma gangrenosum can produce in some cases localization of neutrophilic lesions in other organs such as heart, lymph nodes, and central nervous system which resembles $\mathrm{BD}$ to some extent [11].

Necrotizing Vasculitic Ulcers. Some cases of BD with severe necrotizing vasculitis as a skin manifestation have been described. A case of BD in a 11-year-old Korean boy who had severe necrotizing vasculitis as a skin manifestation was reported [12]. Cutaneous vasculitis in BD is predominantly a venulitis or thrombophlebitis, with relative sparing of the arterial compartment. Vasculopathy [13] reported that approximately half $(48 \%)$ of $\mathrm{BD}$ patients with cutaneous lesions had either lymphocytic (31\%) or leukocytoclastic vasculitis (17\%). They have suggested that vascular inflammation is the pathologic basis of the skin lesions in $\mathrm{BD}$ and that the histologic spectrum ranges from fully developed necrotizing vasculitis with marked fibrinoid necrosis of vessel walls to perivascular inflammation with or without a marked interstitial infiltrate [13-15]. Plotkin et al. [16] reported that a patient with chronic recurrent migratory superficial thrombophlebitis and marked cutaneous hyperreactivity (pathergy) who developed leukocytoclastic vasculitis with recalcitrant leg ulcerations 9 years after the onset of his illness. Cutaneous polyarteritis-nodosa-like lesions and necrotizing panarteritis involving small and medium-sized arteries in the dermis-subcutis junction have also been 


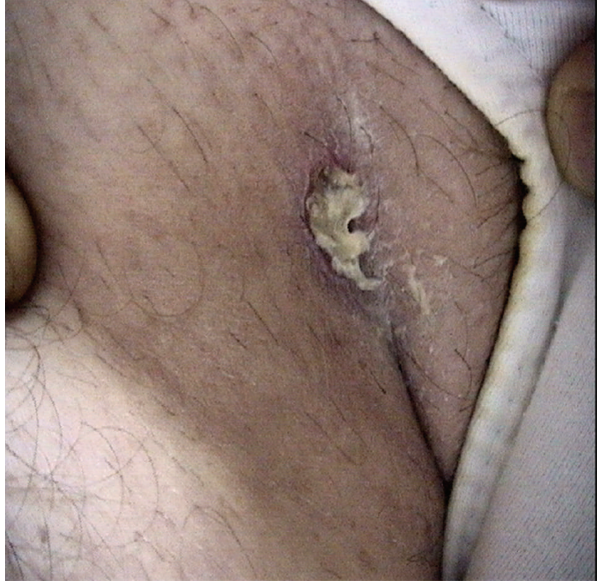

FIgURE 3: Extragenital ulcers.

reported rarely with $\mathrm{BD}$. Vikas et al. [17] reported that their patients had both venous and arterial involvement, the former with thrombotic angiopathy and the latter with acute vasculitis.

\subsection{Systemic Ulcerative Manifestations}

2.2.1. Gastrointestinal System Involvement. Gastrointestinal system involvement in BD affects all areas from the esophagus to the anus. Most authors believe that the gastrointestinal system manifestations of BD should be confined to aphthae, which can occur throughout the gastrointestinal system tract. The frequency of gastrointestinal system involvement varies considerably in different studies and also between different countries. In Japan and Korea the prevalence of gastrointestinal system involvement is higher (15-45\%), whereas in Turkey and Israel the prevalence is much lower $(0-5 \%)$. Some patients with inflammatory bowel disease have been included in series of patients with BD. Gastrointestinal system ulcers were most commonly found in the esophagus, terminal ileum, colon and rectum, and no significant difference was noted in the frequency of gastrointestinal system involvement between the two sexes $[2,4]$. The symptoms include anorexia, vomiting, dyspepsia, diarrhoea and abdominal pain. The ileocaecal ulcers have a distinct tendency to perforate. Intestinal ulcers in $\mathrm{BD}$ are usually multiple and tend to perforate easily, which may lead to an emergency operation $[14,18]$. Transmural inflammation may give rise to fistulae. The ileocaecal region is affected frequently, but any part of the gastrointestinal tract may be involved. Distinguishing BD from inflammatory bowel disease may prove challenging. Ulcers are identical histologically to ulcerative colitis; if present, granulomata suggest Crohn's disease. Pathergy, when positive, points to a diagnosis of $\mathrm{BD}[18,19]$.

\subsection{Diagnostic Investigations}

2.3.1. Laboratory Studies. Although there is no specific laboratory profile to diagnose $\mathrm{BD}$, the key is to obtain maximal history and review of systems with detailed physical examination. A moderate anaemia of chronic disease, a slightly raised neutrophils and/or platelet count is found in around $15 \%$ of patients. The erythrocyte sedimentation rate and Creactive protein are usually moderately elevated but do not correlate well with disease activity. Serum immunoglobulins, especially $\operatorname{IgA}$ and $\operatorname{IgD}$, are sometimes elevated with the presence of circulating immune complexes; complement levels might also be high. Autoantibodies such as rheumatoid factor, antinuclear antibody, anticardiolipin and antineutrophilic antibodies are absent. Disease activity may be assessed by elevated status of neopterin, anti-streptolysin$\mathrm{O}, \alpha 1$-antitrypsin and $\alpha 2$-macroglobulin, all of which are the active components of phagocytic system of polymorphonuclear leukocytes. An elevation in the level of $\beta 2$ microglobulin and myeloperoxidase, generated by activated neutrophils, have also been reported. Cryoglobulinemia, and eosinophilia may occur. HLA analysis should be performed for differential diagnosis in some cases. Abnormalities in the coagulation cascade such as increased levels of fibrinogen, plasminogen activator inhibitor- 1 and circulating factor VIII have been described along with reduced fibrinolytic activity. Known thrombophilic factors such as factor V Leiden and prothrombin gene mutations and protein $\mathrm{C}$ and protein $\mathrm{S}$ deficiency also have been reported to coexist in BD patients by us $[19-21]$.

2.3.2. Skin Tests. Pathergy describes th inappropriately excessive subacute inflammatory reaction to nonspecific injury. It is relatively specific for $\mathrm{BD}$, although it can also be observed in Sweet syndrome, in patients with chronic myeloid leukemia on treatment with interferon- $\alpha$, erythema elevatum diutinum, pyoderma gangrenosum, and also inflammatory bowel disease such as colitis ulcerosa and Chron disease $[2,4]$. The urat crystal test has been found to be more sensitive than the formal pathergy test in the demonstration of abnormal inflammation in $\mathrm{BD}$. The usual response to an intradermal injection of $2.5 \mathrm{mg}$ of urate crystals is an erythematous reaction, maximal at 24 hours and mostly resolved at 48 hours. In $\mathrm{BD}$, the erythematous response is exaggerted, with a greater degree of inflammation present at 24 hours and/or persistance at 48 hours. This test has been reported as having a sensitivity of $\% 61$ and a specificity of $\% 100$ for the diagnosis of BD. The greater sensitivity of the urate crystal test suggests it has clear potential as an aid to the diagnosis of $\mathrm{BD}$, although a positive test may be difficult to demonstrate in patients on anti-inflammatory drugs [2325 .

\section{Diagnosis}

In the absence of a universally accepted diagnostic test, the diagnosis of BD remains purely clinical. In 1990, the International Study Group for BD proposed new diagnostic criteria based on the analysis of 914 patients from several countries. For patients to be classified as having BD, the patients must have recurrent oral ulcers plus at least two of the other criteria including ocular involvement, genital 
Table 1: Differential diagnosis of Behçet's ulcerations.

\begin{tabular}{|c|c|}
\hline Manifestations & Treatments \\
\hline \multirow{18}{*}{ Oral ulcers } & Recurrent oral stomatitis \\
\hline & $\begin{array}{l}\text { PFAPA (Periodic fever, aphthous ulcers, } \\
\text { pharyngitis, adenopathy) }\end{array}$ \\
\hline & Familial Hibernian fever \\
\hline & Sytemic lupus erythematosus \\
\hline & Ulcerative colitis \\
\hline & Coeliac disease and other malabsorption states \\
\hline & Iron, B12 and folate deficiency \\
\hline & Human immunodeficiency virus infections \\
\hline & Chickenpox \\
\hline & Hand, foot and mouth disease \\
\hline & Nicorandil (anal ulcers also reported) \\
\hline & Bisphosphonates \\
\hline & Cyclical neutropenia \\
\hline & Lymphoma \\
\hline & Bullous skin disease \\
\hline & Syphilis \\
\hline & Tuberculosis \\
\hline & Lichen planus \\
\hline \multirow{15}{*}{ Genital ulcers } & Complex aphthosis \\
\hline & Reiter's syndrome \\
\hline & $\begin{array}{l}\text { Mouth and genital ulcers with inflamed } \\
\text { cartilage (MAGIC) }\end{array}$ \\
\hline & Crohn's disease \\
\hline & Sweet's syndrome \\
\hline & Erythema multiforme \\
\hline & Bullous skin disease \\
\hline & Erosive lichen planus \\
\hline & Fixed drug reaction \\
\hline & CMV (in immunocompromised patients) \\
\hline & Herpes simplex (HSV1) \\
\hline & Chancroid \\
\hline & Syphilis \\
\hline & Scabies \\
\hline & Tuberculosis \\
\hline \multirow{6}{*}{$\begin{array}{l}\text { Vasculitic } \\
\text { ulcerations }\end{array}$} & Sweet's syndrome \\
\hline & Pyoderma gangrenosum \\
\hline & Erythema multiforme \\
\hline & Pernio \\
\hline & Leukocytoclastic vasculitis \\
\hline & Polyarteritis nodosa \\
\hline \multirow{3}{*}{$\begin{array}{l}\text { Gastrointestinal } \\
\text { ulcerations }\end{array}$} & Crohn's disease \\
\hline & Coeliac disease \\
\hline & Colitis ulcerosa $[19,22]$ \\
\hline
\end{tabular}

ulcers, skin lesions (erythema nodosum-like lesions and papulopustular eruptions), or the pathergy test in the absence of an alternative clinical diagnosis. It is important to note that a patient who fails to meet the criteria fully may still have BD [26]. Due to orogenital ulcers tendency to spontaneous healing and well-known morphology, biopsies are rarely performed, and, due to similar histopathological features of all variants of ulcers, histopathological examination has a limited value in the differential diagnosis. Lymphocytes, macrophages, and neutrophils are observed at the base of oral ulcers. The infiltrate is more pronounced around the vessels. Although classified as vasculitis, some studies report that most mucocutaneous lesions in $\mathrm{BD}$ do not present typical characteristics of an actual vasculitis. Fibrinoid necrosis in the vessel walls is reported to be very rare. At the periphery of the ulcer base, the infiltrate may penetrate into the epidermis. Some recently published direct immunofluorescence studies report IgM and $\mathrm{C}_{3}$ deposits in perivascular region with or without granular $\mathrm{C}_{3}$ deposits at the dermoepidermal junction in the perilesional skin of oral ulcers in BD patients. Also in another study, Wilhelmsen et al. evaluated perilesional skin of 23 oral ulcer patients with direct immunoflourescence and found out the immunocomplexes to be absent $[9,26]$ (Table 1).

\section{Differential Diagnosis}

It usually is not difficult to recognize the full-blown syndrome of $\mathrm{BD}$, but the so-called incomplete forms sometimes cause problems. Therefore, other causes of oculomucocutaneous syndromes should carefully be excluded including autoimmune bullous skin diseases, erythema multiforme major, Reiter syndrome, seronegative arthropathies, sarcoidosis, Sweet syndrome, cicatricial pemphigoid, celiac disease, and pemphigus vulgaris. Similarly, herpes simplex virus infection, lichen planus, syphilis, systemic lupus erythematosus, ulcerative colitis, and mixed connective tissue diseases may also cause oral and cutaneous ulcers. Oral ulcers alone should be differentiated from recurrent aphtous stomatitis, erythema multiforme, toxic epidermal necrolysis, syphilis, tuberculosis orificialis, inflammatory bowel diseases, and erosive lichen planus. Genital ulcerations should be differentiated from venereal diseases such as chancroid, syphilis, scabies, and herpes simplex virus infection. Similarly, recurrent orogenital ulcerations are also seen in hypereosinophilic syndrome, myelodysplastic syndrome, Munchausen syndrome (pseudo-BD), pemphigus vulgaris, tuberculosis cutis, and acquired immunedeficiency syndrome $[2,4,19,22]$.

\section{Treatment}

Treatment of the various symptoms of BD remains controversial because of the heterogenity of the condition, lack of reliable laboratory markers of disease activity, and paucity of controlled clinical trials and unstandardized outcome measures for this disease (Table 2).

\subsection{Therapy of Ulcerations}

5.1.1. Mucocutaneous Ulcers. In mild forms of the mucocutaneous ulcerations, initial treatment consists of mild diet, 
TABLe 2: Therapy of types/condition and Floor Chart of 1st, 2nd, 3rd line medicine.

(a) Topical treatments of ulcerations

\begin{tabular}{|c|c|c|c|}
\hline Treatment & Dose & Used as first-line therapy & Used as alternative therapy \\
\hline Topical steroids & 3 times a day topically & Oral and genital ulcers & \\
\hline$\% 5$ Amlexanox paste & 4/day topically & Oral ulcers & \\
\hline Sucralfate suspension & 4/day topically for 3 months & Orogenital ulcers & \\
\hline $\begin{array}{l}\text { Triamcinolone acetonide } 40 \mathrm{mg} \\
\text { ampule }\end{array}$ & Intralesionally $5 \mathrm{mg} / \mathrm{mL}$ & Severe orogenital ulcers & \\
\hline Lidocaine $\% 2-5$ & $\begin{array}{l}\text { 4/day topically as mouthwashes, } \\
\text { before meals }\end{array}$ & $\begin{array}{l}\text { Severe and multiple oral ulcers in } \\
\text { Behçet's patients with } \\
\text { insufficients oral intake by pain, }\end{array}$ & \\
\hline $\begin{array}{l}\text { Chlorhexidine gluconate rinses } \\
\% 1-2\end{array}$ & Topically as mouthwashes & Oral ulcers & \\
\hline Tetracycline & $\begin{array}{l}250 \mathrm{mg} \text { in } 5 \mathrm{~mL} \text { water solution, } \\
\text { held in mouth for } 2 \text { min once a } \\
\text { day }\end{array}$ & & Oral ulcers \\
\hline rhGM-CSF $300 \mu \mathrm{g}$ ampule & $\begin{array}{l}\text { Intralesionally injection in every } \\
2 \text { weeks }\end{array}$ & & Large genital ulcers \\
\hline
\end{tabular}

(b) Systemic treatments

\begin{tabular}{|c|c|c|c|}
\hline Treatment & Dose & Used as first-line therapy & Used as alternative therapy \\
\hline Systemic steroids & 5-100 mg/day orally & & $\begin{array}{c}\text { Orogenital and } \\
\text { gastrointestinal ulcerations }\end{array}$ \\
\hline Colchicine & $0.5-1.5 \mathrm{mg} /$ day orally & Oral and genital ulcers & \\
\hline Thalidomide & $100-300 \mathrm{mg} /$ day orally & & Orogenital ulcers \\
\hline Dapsone & 100 mg/day orally & & Oral and genital ulcers \\
\hline Pentoxifylline & $300 \mathrm{mg} /$ day orally & & Orogenital and leg ulcers \\
\hline Levamisole & $\begin{array}{l}150 \mathrm{mg} \text { in } 3 \text { doses/day every } 2 \\
\text { day } \times 1 \text { week }\end{array}$ & & Mucocutaneous ulcers \\
\hline Penicilline & $1.2 \times 10^{6} \mathrm{U} / 3$ week & & Mucocutaneous ulcers \\
\hline Azithromycin & $\begin{array}{l}500 \mathrm{mg} 3 \text { times a week for } 4 \\
\text { weeks }\end{array}$ & & Mucocutaneous ulcers \\
\hline Interferon- $\alpha$ & 5 million U/day im or s.c. & & Mucocutaneous ulcers \\
\hline Sulfasalazine & 1-3 gr/day orally & Gastrointestinal ulcers & \\
\hline Surgery & & & Gastrointestinal ulcers \\
\hline \multicolumn{4}{|l|}{ Combination therapies } \\
\hline Penicilline + colchicine & $\begin{array}{l}\text { Penicilline } 1.2 \times 10^{6} \mathrm{U} / 3 \text { week, } \\
\text { colchicine } 1.5 \mathrm{mg} / \text { day }\end{array}$ & & Mucocutaneous ulcers \\
\hline
\end{tabular}

and avoidance of hard, spicy, or salty nutrients and chemicals. Topical treatment of oral ulcers includes caustic solutions (silver nitrate \%1-2, tinctura myrrhae $\% 5-10 \mathrm{w} / \mathrm{v}$, hydrogen peroxides $\% 0.5$, and methyl violet $\% 0.5$ ) $1-2 \times /$ day, topical antiseptic and anti-inflammatory drugs (amlexanox $\% 5$ in oral paste, rebamipine, hexetidine \%1, chlorhexidine \%1-2 mouth-wash solutions, benzydamine, camomile extracts, and tetracycline mouth-wash) and also glycerine solution $250 \mathrm{mg} / 5 \mathrm{~mL}$ glycerine for $2 \mathrm{~min}$, 4-6×/day, topical corticosteroids (triamcinolon mucosal ointment, dexamethasone mucosal paste, and betamethasone pastilles) $4 \times /$ day or during the night or intrafocal infiltrations with triamcinolone suspension $0.1-0.5 \mathrm{~mL}$ per lesion, topical anaesthetics (lidocaine \%2-5, mepivacaine \%1.5, tetracaine \%0.5-1 gels or mucosal ointments) 2-3/day, topical sucralfate (suspension, $1 \mathrm{gr} / 5 \mathrm{~mL}$ ) $4 \times /$ day, 3 months durations as mouthwash, topical aminosalicylic acid (\%5 cream) $3 \times /$ day $^{5}$. In daily practice, the contents of a tetracycline capsule ( $250 \mathrm{mg}$ ) can be dissolved in $5 \mathrm{~mL}$ of water, holding in the mouth for about 2 minutes (four times a day). BD patients with insufficient oral intake caused by pain can be treated with topical lidocaine (2-5\%) applications before meals and oral anti-inflammatory rinses containing chlorhexidine gluconate (1-2\%) [27-31]. 
In topical treatment of genital ulcers and cutaneous ulcers, corticosteroid and antiseptic creams can be applied for a short period of time like 7 days. Painful genital ulcers can be managed by topical anaesthetic in cream [5]. Topical sucralfate reduces the healing duration and pain of genital ulcers like oral ulcers. Sucralfate has been used in the treatment of orogenital ulcerations [27]. For severe ulcers, intralesional corticosteroid (triamcinolone acetonide) may be helpful. Corticosteroid injections like triamcinolone 0.1$0.5 \mathrm{~mL} /$ lesions can be focally applied in recalcitran ulcerations. Bacanli et al. studied the efficacy of topically applied granulocyte colony-stimulating factor in the treatment of oral and genital ulcers. It decreased the healing time and pain of both ulcers in 6 of 7 patients compared with the pretreatment period. The effectiveness of the treatment, however, did not continue during the posttreatment period [32]. In a randomized, controlled, crossover double-blind trial, zinc sulfate treatment decreased the mucocutaneous ulcerations index after the first month of therapy. After shifting to placebo treatment, the clinical index started to increase but remained significantly lower than levels before therapy [32-34].

In severe forms of the mucocutaneous ulcerations, additional systemic treatment is required. The following drugs have proven beneficial: Corticosteroids (prednisolone, initial dose 30-60 mg/day p.o. for at least 4 weeks) can be administered as monotherapy or in combination with colchicine (1$2 \mathrm{mg} /$ day p.o.), dapsone (100-150 mg/day p.o.), interferon- $\alpha$ (3-12 million IU/3× week s.c.), or azathioprine (initial dose $100 \mathrm{mg} /$ day p.o.). Nonsteroidal anti-inflammatory drugs, like indomethacin ( $100 \mathrm{mg} /$ day p.o. over 3 months) can be effective on the mucocutaneous lesions. Pentoxifylline (300 mg 1-3×/day p.o.) and oxypentifylline (400 mg $3 \times /$ day p.o.) treatment for 1 month induced a remission of oral ulcers. Pentoxifylline decreases superoxide production by neutrophils. High dosage of oral or pulse intravenous steroids may be indicated for large and refractory mouth ulcers larger than $10 \mathrm{~mm}$ or when the oropharynx is compromised. Severe mucocutaneous disease and arthritis may be treated with systemic corticosteroids in combination with azathioprine [35-39].

Colchicine (0.5-2 mg/day p.o.) can be used as a secondline alternative treatment. A recent randomized double-blind and placebo-controlled study has shown that colchicine reduces the occurence of genital ulcers among women. Colchicine inhibits the enhanced chemotactic activity of neutophils. Colchicine seldom eliminates oral ulcerations completely, but may reduce to an acceptable level the frequency and severity of oral ulcer $[40,41]$.

There is little evidence that antibacterials or antivirals are useful in the therapy of mucocutaneous ulcerations. There is some evidence that adjunctive penicillin treatment may enhance the clinical response to colchicine therapy for both orogenital ulcers. It has been proposed, although not proven, that an etiologic relationship exists between streptococcal infection and BD. In an uncontrolled study, benzathine penicillin improved the ulcerative manifestations of disease. Patients with mucocutaneous ulcerations had complete recovery in 5 to 20 days. In a retrospective study, benzathine penicillin had a beneficial effect on oro-genital ulcers. A prospective randomized study compared the efficacy of colchicine with colchicine and benzathine penicillin over 24 months. They reported the effectiveness of benzathine penicillin and colchicine on the mucocutaneous ulcerations, benefits not achieved with colchicine monotherapy. The result of an open study with minocycline treatment for 3 months were reported and it was observed that oro-genital ulcers improved at a rate of $\% 10$ to 100 [42-45].

Dapsone (100-150 mg/day p.o.) also inhibits the enhanced chemotactic activity of neutrophils and can be used as an alternative drug to colchicine. Quick relapses have been found after discontinuation of dapsone treatment. Intermittant ascorbic acid treatment (vitamin C; $500 \mathrm{mg} /$ day) is advisable to prevent increased methaemoglobin serum levels. Its use is often complicated by haemolytic anemia, even in patients with normal glucose-6-phosphate-dehyrogenase activity [46].

Interferon- $\alpha$ has been successfully used in the treatment of BD. Its immunomodulatory effect, ability to augment the decreased activity of the patient's natural killer cells, capacity to intibit neovascular proliferation, and antiviral activity have been suggested to explain its action in BD. It was shown to markedly inhibit IL-8 synthesis and secretion form endothelial cells. Interferon- $\alpha$-2a treatment at dose of 6 million IU/3× week s.c. for 3 months, is an effective alternative treatment, particularly for management of mucocutaneous ulcerations [47].

Azathiopurine (2.5 mg/kg body weight/day p.o.) has been found to be an effective choice in oral and genital ulcers in a randomized, double-blind and placebo controlled study [48].

Cyclosporin A (3 mg/kg/day p.o.) is capable of markedly ameliorating mucocutaneous ulcers. But, it should be reserved for the most severe patients because of its significant long-term adverse effects [49].

Methotrexat (7.5-20 mg/1× weekly p.o. over 1 month) is able to induce an improvement of a severe mucocutaneous ulcers [50].

Thalidomide (100-300 mg/day orally, optimal dose $100 \mathrm{mg} /$ day in the evening for 8 weeks) has been approved for the treatment of male and sterilised or postmenapausal women with BD. Thalidomide was shown to selectively inhibit TNF- $\alpha$ synthesis by monocytes. In a randomized, double-blind placebo-controlled study with $63 \mathrm{BD}$ patients, a remission of oral and genital ulcers was detected in \%24 of the patients over 2 months. During the 6-month treatment, $\% 30$ of the patients with $\mathrm{BD}$ remained free of mucocutaneous ulcerations. Discontinuation of the treatment results in oro-genital ulcers recurrences; therefore, a maintenance treatment with $50 \mathrm{mg} /$ day to $50 \mathrm{mg}$ twice a week is recommended. Thalidomide is often highly effective at reducing the frequency and severity of mucocutaneous ulcerations resistant to colchicine. However, its widespread use is clearly limited teratogenic and neuropathic complications. The risk of developing irreversible peripheral neuropathy is thought to increase in a dose-dependant fashion, and so thalidomide should be recommended at the lowest dose possible to control symptoms, for example, $50 \mathrm{mg}$ daily or $100 \mathrm{mg}$ 
3 times a week. Since thalidomide can be sedating, it is best taken at night [51-53].

Recent studies of anti-TNF agents such as infliximab (i.v. $0,2,4,8$ months), and etanercept (s.c. twice a week) have shown favorable results. Infliximab was also efficacious in extraocular manifestations, such as oral and genital ulcers in the majority of patients in three self-controlled studies. Almoznino et al. described a case of Behçet's syndrome in a 48-year-old woman whose oral ulcers were resistant to a wide range of topical and systemic treatments and remained unchanged for 7 weeks. Administration of a single dose of infliximab resulted in complete remission and recovery of the mouth aphtae within 7 days. Additional case series and case reports suggested that patients with severe mucocutaneous lesions exhibit rapid and good responses to infliximab administration, mostly using $5 \mathrm{mg} / \mathrm{kg}$ or $3 \mathrm{mg} / \mathrm{kg}$. Some patients with orogenital ulcers unresponsive and/or intolerant to conventional treatments remained disease-free for the first time in years. Almost all patients were resistant to conventional treatments, and were treated with infliximab alone or as an add-on therapy. In a double-blind, placebocontrolled study of 40 male patients with BD, Melikoglu et al. reported that etanercept ( $25 \mathrm{mg}$ twice/week, for 4 weeks) was effective in suppressing most mucocutaneous lesions. The drug had a clear effect on oral ulcers, and the response was evident as early as the first week. Almost half of the patients receiving etanercept were free of oral ulcers at the end of the study compared with 5\% of the placebo group. Although, the drug decreased the number of genital ulcers and arthritis episodes during the treatment period, the difference was not significant $[54,55]$.

Lactobacilli, which have antiinflammatory activity, may be useful in some diseases, particularly in inflammatory bowel disease. In a study aimed at evaluating the efficacy of lactobacilli lozenges in the management of oral ulcers of $\mathrm{BD}$, a significant decrease in the mean number of ulcers was found following treatment, especially among women [56].

5.1.2. Gis Ulcerations. The treatments used for inflammatory bowel disease including sulfasalazine and corticosteroids are also useful for the gastrointestinal lesions of $\mathrm{BD}$. The dose of corticosteroids depends on the severity of lesions. Bowel rest is obligatory in patients with an acute abdomen and bleeding. Surgery is considered for patients with bowel perforation and persistant bleeding. Invasive surgical procedures often result in excessive infiltration of inflammatory cells into the treated tissues, with subsequent anastomotic leakage. To prevent this complication, undetermined doses of corticosteroids are given to the patients for several days after surgery. Even if the operation is successful, repeated operation because of recurrence is required in about half of the patients. There was a suggestion that azathiopurine use was helpful. The rate of reoperation can be lowered by using azathopurine in patients with entero-BD. Intraarterial steroid injections into the mesenteric arteries were found to be effective in severe entero-BD unresponsive to conventional treatments [57] (Table 3).
TABLE 3

\begin{tabular}{|c|c|}
\hline Manifestations & Treatments \\
\hline \multirow{3}{*}{ Oral ulcers } & $\begin{array}{l}\text { 1st line: Topical triamcinolone acetonide, } \\
\text { prednisolone, amlexonax, } \\
\text { anti-inflammatory rinses, topical } \\
\text { anaesthetics }\end{array}$ \\
\hline & $\begin{array}{l}\text { 2nd line: Topical sucralfate, aminosalicylic } \\
\text { acid, caustic solutions, oral tetracycline } \\
\text { solutions, colchicine, levamisole, } \\
\text { thalidomide, pulse methyl prednisolone, } \\
\text { intralesional trimcinolone acetonide }\end{array}$ \\
\hline & $\begin{array}{l}\text { 3rd line: Cyclosporine, azathiopurine, } \\
\text { methotrexate, chlorambucil, infliximab, } \\
\text { etanercept, plasmapheresis-apheresis, zinc } \\
\text { sulphate, penicilline, azithromycin, } \\
\text { minocycline, dapsone, pentoxifylline, } \\
\text { interferon- } \alpha\end{array}$ \\
\hline \multirow[t]{2}{*}{ Genital ulcers } & $\begin{array}{l}\text { 1st line: Topical triamcinolone acetonide, } \\
\text { sucralfate, oral colchicine, azathiopurine, } \\
\text { dapsone, prednisolone }\end{array}$ \\
\hline & $\begin{array}{l}\text { 2nd line: Levamisole, interferon- } \alpha \text {, } \\
\text { methotrexate, thalidomide, cyclosporine A }\end{array}$ \\
\hline \multirow[t]{2}{*}{$\begin{array}{l}\text { Vasculitic } \\
\text { ulcerations }\end{array}$} & $\begin{array}{l}\text { 1st line: Topical bethametasone, oral } \\
\text { colchicine, azathiopurine, dapsone, } \\
\text { prednisolone }\end{array}$ \\
\hline & $\begin{array}{l}\text { 2nd line: Levamisole, dapson, interferon- } \alpha \text {, } \\
\text { thalidomide, azitromycin, pentoxifylline }\end{array}$ \\
\hline \multirow{3}{*}{$\begin{array}{l}\text { Gastrointestinal } \\
\text { involvement }\end{array}$} & 1st line: Sulfasalazine, corticosteroids \\
\hline & $\begin{array}{l}\text { 2nd line: Cyclosporine A, azathiopurine, } \\
\text { surgery }\end{array}$ \\
\hline & $\begin{array}{l}\text { 3rd line: İntraarterial corticosteroids } \\
\text { injections }\end{array}$ \\
\hline
\end{tabular}

Behçet's disease is a multisystemic inflammatory disease of unknown etiology which usually occurs as ulcerative manifestations: aphthous stomatitis and genital ulcerations. At the beginning of the disease the diagnosis is uncertain because of various clinical manifestations and a long period up to the full clinical picture manifestation. Since neither the laboratory data nor the histopathological signs are truly pathognomonic in Behçet's disease, the differential diagnosis depends on a careful evaluation of the medical history and meticulous physical examination to detect concomitant systemic manifestations. Sometimes, some laboratory test may help establish the diagnosis. Subspecialty referral to ophthalmology, rheumatology, neurology, and gastroenterology should be considered when indicated.

\section{References}

[1] H. Behçet, "Uber rezidivierende aphthouse durch ein virus verursachte Geschwuere am Mund, am Auge und an den Genitalien," Dermatologische Wochenschrift, vol. 105, pp. 11521157, 1937.

[2] A. Gurler, A. Boyvat, and U. Tursen, "Clinical manifestations of Behçet's disease: an analysis of 2147 patients," Yonsei Medical Journal, vol. 38, no. 6, pp. 423-427, 1997. 
[3] G. Azizlerli, A. A. Kose, R. Sarica et al., "Prevalence of Behcet's disease in Istanbul, Turkey," International Journal of Dermatology, vol. 42, pp. 803-806, 2003.

[4] U. Tursen, A. Gurler, and A. Boyvat, "Evaluation of clinical findings according to sex in 2313 Turkish patients with Behçet's disease," International Journal of Dermatology, vol. 42, no. 5, pp. 346-351, 2003.

[5] E. Alpsoy, C. Zouboulis, and G. E. Ehrlich, "Mucocutaneous lesions of Behçet's disease," Yonsei Medical Journal, vol. 48, no. 4, pp. 573-585, 2007.

[6] P. Scheid, A. Bohadana, and Y. Martinet, "Nicotine patches for aphthous ulcers due to Behcet's syndrome," New England Journal of Medicine, vol. 343, no. 24, pp. 1816-1817, 2000.

[7] M. C. Mat, N. Goksugur, B. Engin, S. Yurdakul, and H. Yazici, "The frequency of scarring after genital ulcers in Behçet's syndrome: a prospective study," International Journal of Dermatology, vol. 45, no. 5, pp. 554-556, 2006.

[8] S. Rashtak and M. Pittelkow, "Skin involvement in systemic autoimmune diseases," Current Directions in Autoimmunity, vol. 10, pp. 344-358, 2008.

[9] O. Gündüz, "Histopathological evaluation of behçet's disease and identification of new skin lesions," Pathology Research International, vol. 2012, Article ID 209316, 7 pages, 2012.

[10] H. Yazici, I. Fresko, V. Hamuryudan et al., "Behçet's syndrome: the cerrahpasa experience," Advances in Experimental Medicine and Biology, vol. 455, pp. 135-140, 1999.

[11] J. W. Kim, J. H. Park, D. Lee, S. W. Hwang, and S. W. Park, "Vegetative pyoderma gangrenosum in Behçet's disease," Acta Dermato-Venereologica, vol. 87, no. 4, pp. 365-367, 2007.

[12] M. Melikoglu, E. Kural-Seyahi, K. Tascilar, and H. Yazici, "The unique features of vasculitis in Behçet's syndrome," Clinical Reviews in Allergy and Immunology, vol. 35, no. 1-2, pp. 4046, 2008.

[13] O. S. Vasculopathy, "Behcet's syndrome, and familial Mediterranean fever," Current Opinion in Rheumatology, vol. 11, pp. 393-398, 1999.

[14] I. Krause and A. Weinberger, "Behcet's disease," Current Opinion in Rheumatology, vol. 20, pp. 82-87, 2008.

[15] U. Türsen, B. Ulubas, T. Irfan Kaya, H. Pekdemir, and G. Ikizoğlu, "Cardiac complications in Behçet's disease," Clinical and Experimental Dermatology, vol. 27, no. 8, pp. 651-653, 2002.

[16] G. R. Plotkin, B. R. Patel, and V. N. Shah, "Behçet's syndrome complicated by cutaneous leukocytoclastic vasculitis. Response to prednisone and chlorambucil," Archives of Internal Medicine, vol. 145, no. 10, pp. 1913-1915, 1985.

[17] A. Vikas, S. Atul, R. Singh, L. Sarbmeet, and H. Mohan, "Behçet's disease with relapsing cutaneous polyarteritisnodosa-like lesions, responsive to oral cyclosporine therapy," Dermatology Online Journal, vol. 9, no. 5, p. 9, 2003.

[18] S. E. Marshall, "Behçet's disease," Best Practice and Research: Clinical Rheumatology, vol. 18, no. 3, pp. 291-311, 2004.

[19] C. Evereklioglu, "Current concepts in the etiology and treatment of Behçet disease," Survey of Ophthalmology, vol. 50, no. 4, pp. 297-350, 2005.

[20] J. Andrews and D. O. Haskard, "Current management options in behçet's disease," Minerva Medica, vol. 93, no. 5, pp. 335$345,2002$.

[21] M. C. Pickering and D. O. Haskard, "Behçet's syndrome," Journal of the Royal College of Physicians of London, vol. 34, no. 2, pp. 169-177, 2000.

[22] A. Kokturk, "Clinical and pathological manifestations with differential diagnosis in Behçet's disease," Pathology Research International, vol. 2012, Article ID 690390, 9 pages, 2012.
[23] I. Krause, Y. Molad, M. Mitrani, and A. Weinberger, "Pathergy reaction in Behcet's disease: lack of correlation with mucocutaneous manifestations and systemic disease expression," Clinical and Experimental Rheumatology, vol. 18, no. 1, pp. 7174, 2000.

[24] Ü. Gül and M. Gönül, “Oral and genital pathergy in Behçet's disease," Dermatology, vol. 215, no. 1, pp. 80-81, 2007.

[25] J. Andrews and D. O. Haskard, "Current management options in behçet's disease," Minerva Medica, vol. 93, no. 5, pp. 335345, 2002.

[26] E. Alpsoy, L. Donmez, M. Onder et al., "Clinical features and natural course of Behçet's disease in 661 cases: a multicentre study," British Journal of Dermatology, vol. 157, no. 5, pp. 901906, 2007.

[27] E. Alpsoy and A. Akman, "Behçet's disease: an algorithmic approach to its treatment," Archives of Dermatological Research, vol. 301, no. 10, pp. 693-702, 2009.

[28] A. Khandwala, R. G. Van Inwegen, and M. C. Alfano, " $5 \%$ amlexanox oral paste, a new treatment for recurrent minor aphthous ulcers: I. Clinical demonstration of acceleration of healing and resolution of pain," Oral Surgery, Oral Medicine, Oral Pathology, Oral Radiology, and Endodontics, vol. 83, no. 2, pp. 222-230, 1997.

[29] C. Tanaka, T. Matsuda, Y. Yukinari, H. Yamada, Y. Ichikawa, T. Sakane et al., "The beneficial effect of rebamipide on recurrent oral aphthous ulcers in Behcet's disease," in Behcet's Disease, M. Hamza, Ed., pp. 477-480, Pub Adhoua, Tunis, Tunisia, 1997.

[30] E. Alpsoy, H. Er, C. Durusoy, and E. Yilmaz, "The use of sucralfate suspension in the treatment of oral and genital ulceration of Behcet disease: a randomized, placebo-controlled, doubleblind study," Archives of Dermatology, vol. 135, no. 5, pp. 529532, 1999.

[31] M. A. G. Edres, C. Scully, and M. Gelbier, "Use of proprietary agents to relieve recurrent aphthous stomatitis," British Dental Journal, vol. 182, no. 4, pp. 144-146, 1997.

[32] N. Alli, G. Karakayali, I. Kahraman, and F. Artuz, "Local intralesional therapy with rhGM-CSF for a large genital ulcer in Behcet's disease," British Journal of Dermatology, vol. 136, no. 4, pp. 639-640, 1997.

[33] I. Kotter, H. Durk, J. Saal, G. Fierlbeck, U. Pleyer, and M. Zierhut, "Therapy of Behcet's disease," German Journal of Ophthalmology, vol. 5, pp. 92-97, 1996.

[34] K. E. Sharquie, R. A. Najim, W. S. Al-Dori, and R. K. AlHayani, "Oral zinc sulfate in the treatment of Behcet's disease: a double blind cross-over study," Journal of Dermatology, vol. 33, no. 8, pp. 541-546, 2006.

[35] V. G. Kaklamani and P. G. Kaklamanis, "Treatment of behçet's disease-an update," Seminars in Arthritis and Rheumatism, vol. 30, no. 5, pp. 299-312, 2001.

[36] H. Yazici, S. Yurdakul, and V. Hamuryudan, "Behçet disease," Current Opinion in Rheumatology, vol. 13, no. 1, pp. 18-22, 2001.

[37] J. M. M. Gardner-Medwin, N. J. Smith, and R. J. Powell, "Clinical experience with thalidomide in the management of severe oral and genital ulceration in conditions such as Behcet's disease: use of neurophysiological studies to detect thalidomide neuropathy," Annals of the Rheumatic Diseases, vol. 53, no. 12, pp. 828-832, 1994.

[38] P. De Merieux, L. E. Spitler, and H. E. Paulus, "Treatment of Behcet's syndrome with levamisole," Arthritis and Rheumatism, vol. 24, no. 1, pp. 64-70, 1981. 
[39] I. Fresko, S. Yurdakul, V. Hamuryudan et al., "The management of Behcet's syndrome," Annales de Medecine Interne, vol. 150, no. 7, pp. 576-581, 1999.

[40] E. Aktulga, M. Altac, and A. Muftuoglu, "A double blind study of colchicine in Behcet's disease," Haematologica, vol. 65, no. 3, pp. 399-402, 1980.

[41] S. Yurdakul, C. Mat, Y. Tuzun et al., "A double-blind trial of colchicine in Behcet's syndrome," Arthritis and Rheumatism, vol. 44, pp. 2686-2692, 2001.

[42] S. Okten, "Penicillin in treatment of Behcet's disease," in Behcet's Disease: Basic and Clinical Aspects, J. D. O'Duffy and E. Kokmen, Eds., pp. 645-648, Marcel Dekker, New York, NY, USA, 1991.

[43] I. C. Haznedaroglu, H. Demiroglu, O. I. Ozcebe, O. Ozdemir, and S. V. Dundar, "Benzathine-penicillin in the prophylaxis and treatment of Behcet's disease," in Proceedings of the 7th Mediterranean Congress of Rheumatology, K. A. Boki, A. A. Drosos, H. M. Moutsopoulos, A. G. Tzioufas, and P. G. Vlachoyiannopoulos, Eds., pp. 185-188, Monduzzi Editore, Athens, Greece, 1994.

[44] M. Çalgüneri, I. Ertenli, S. Kiraz, M. Erman, and I. Çelik, "Effect of prophylactic benzathine penicillin on mucocutaneous symptoms of Behçet's disease," Dermatology, vol. 192, no. 2, pp. 125-128, 1996.

[45] N. Oyama, M. Inoue, T. Matsui, Y. Nihei, A. Nishibu, and F. Kaneko, "Minocycline effects on the clinical symptoms in correlation with cytokines produced by peripheral blood mononuclear cells stimulated with streptococcal antigens in Behcet's disease," in Behcet's Disease, M. Hamza, Ed., pp. 481486, Pub Adhoua, Tunis, Tunisia, 1997.

[46] T. Sakane, M. Takeno, N. Suzuki, and G. Inaba, "Behcet's disease," New England Journal of Medicine, vol. 341, no. 17, pp. 1284-1291, 1999.

[47] E. Alpsoy, C. Durusoy, E. Yilmaz et al., "Interferon alfa-2a in the treatment of Behçet disease: a randomized placebocontrolled and double-blind study," Archives of Dermatology, vol. 138, no. 4, pp. 467-471, 2002.

[48] H. Yazici, H. Pazarli, C. G. Barnes et al., "A controlled trial of azathioprine in Behcet's syndrome," New England Journal of Medicine, vol. 322, no. 5, pp. 281-285, 1990.

[49] D. BenEzra, E. Cohen, T. Chajek et al., "Evaluation of conventional therapy versus cyclosporine A in Behcet's syndrome," Transplantation Proceedings, vol. 20, no. 3, pp. 136-143, 1988.

[50] J. L. Jorizzo, W. L. White, C. M. Wise, M. D. Zanolli, and E. F. Sherertz, "Low-dose weekly methotrexate for unusual neutrophilic vascular reactions: cutaneous polyarteritis nodosa and Behcet's disease," Journal of the American Academy of Dermatology, vol. 24, no. 6, pp. 973-978, 1991.

[51] J. L. Jorizzo, F. C. Schmalstieg, and A. R. Solomon, "Thalidomide effects in Behcet's syndrome and pustular vasculitis," Archives of Internal Medicine, vol. 146, no. 5, pp. 878-881, 1986.

[52] T. Saylan and I. Saltik, "Thalidomide in the treatment of Behcet's syndrome," Archives of Dermatology, vol. 118, no. 8, p. 536, 1982.

[53] A. M. Denman, E. Graham, L. Howe, E. Y. Denman, and S. Lightman, "Low dose thalidomide treatment of Behcet's syndrome," in Behcet's Disease, B. Wechsler and P. Godeau, Eds., International Congress Series, pp. 649-653, Excerpta Medica, Amsterdam, The Netherlands, 1992.

[54] P. P. Sfikakis, N. Markomichelakis, E. Alpsoy et al., "Anti-TNF therapy in the management of Behçet's disease-review and basis for recommendations," Rheumatology, vol. 46, no. 5, pp. 736-741, 2007.

[55] M. Melikoglu, I. Fresko, C. Mat et al., "Short-term trial of etanercept in Behçet's disease: a double blind, placebo controlled study," Journal of Rheumatology, vol. 32, no. 1, pp. 98-105, 2005.

[56] L. Tasli, C. Mat, C. De Simone, and H. Yazici, "Lactobacilli lozenges in the management of oral ulcers of Behçet's syndrome," Clinical and Experimental Rheumatology, vol. 24, pp. S83-S86, 2006.

[57] H. Larsson, "Treatment of severe colitis in Behcet's syndrome with thalidomide (CG-217)," Journal of Internal Medicine, vol. 228, no. 4, pp. 405-407, 1990. 


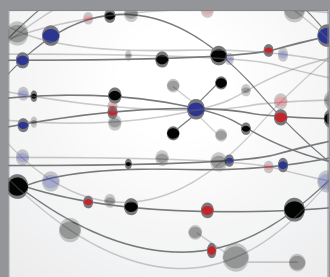

The Scientific World Journal
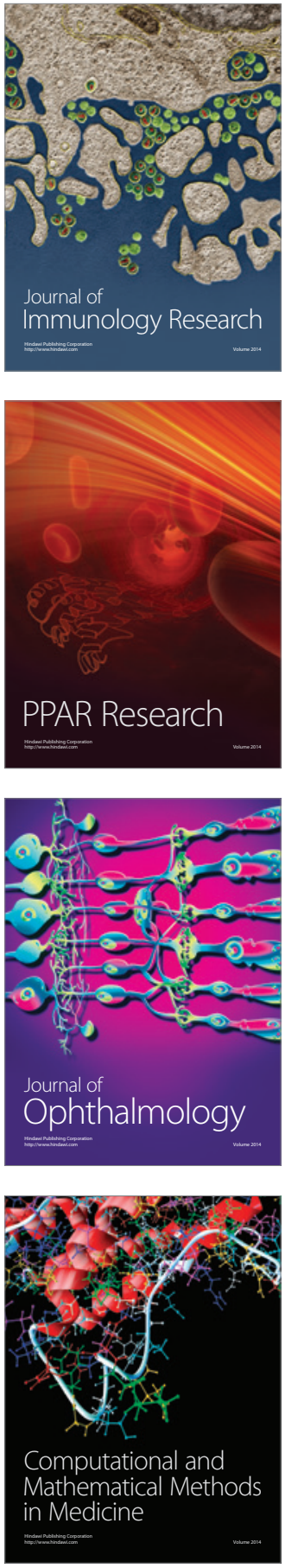

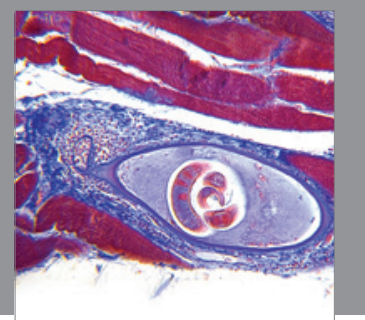

Gastroenterology

Research and Practice
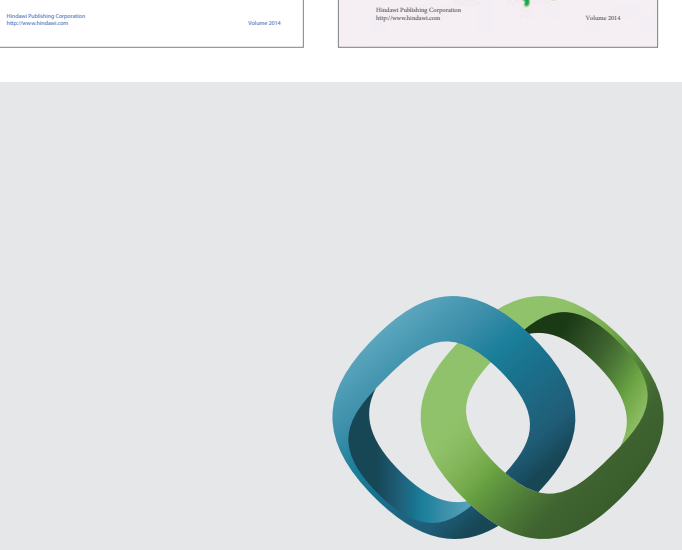

\section{Hindawi}

Submit your manuscripts at

http://www.hindawi.com
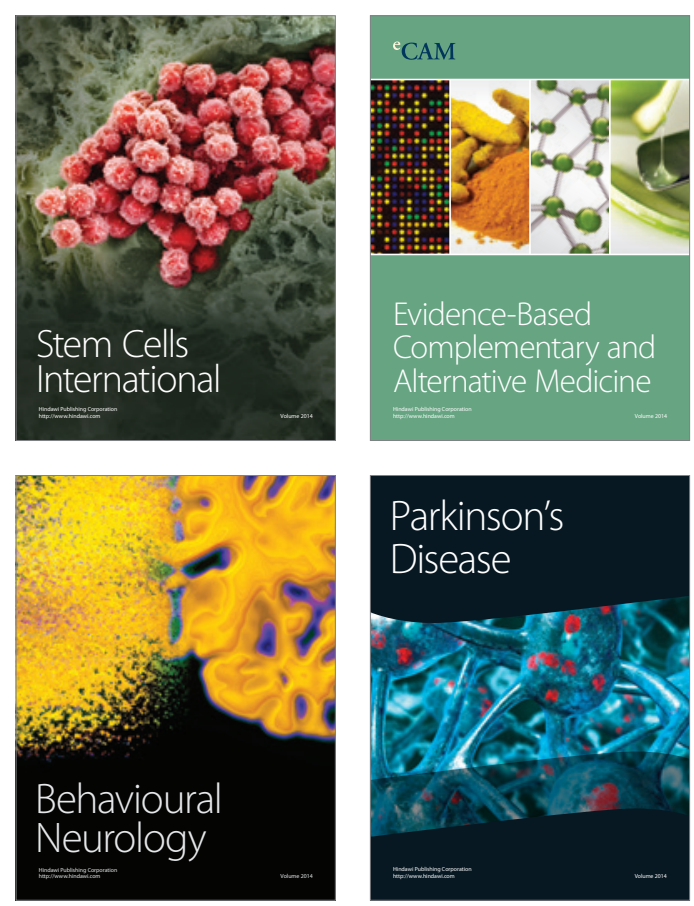

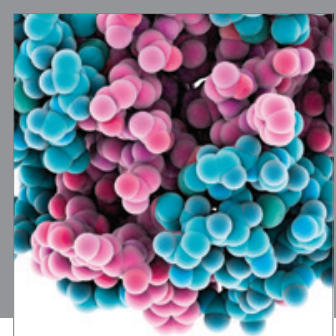

Journal of
Diabetes Research

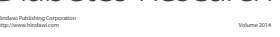

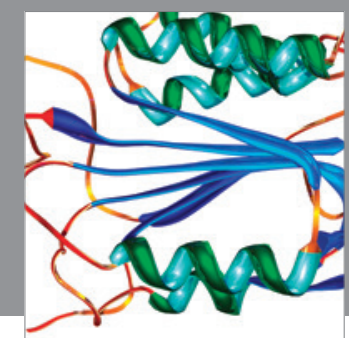

Disease Markers
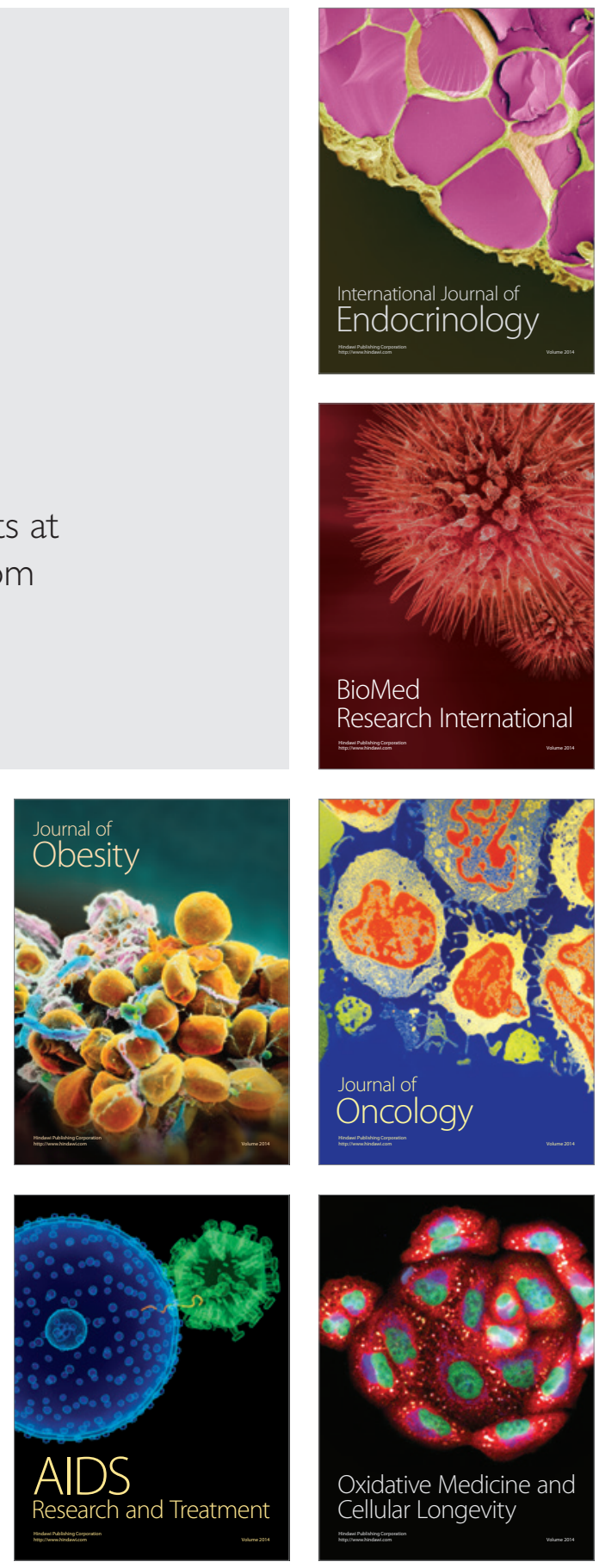